\title{
PROSPECTIVAS ANTROPOLÓGICAS Y DESARROLLO RURAL
}

\author{
Anthropological Prospectives and Rural Development \\ Prospectivas antropológicas e desenvolvimento rural
}

\author{
Carlos MONTES PÉREZ \\ Universidad de Salamanca \\ Centro Asociado de la UNED. Ponferrada, León \\ cmontes@usal.es
}

\section{PRESENTACIÓN}

El presente número monográfico titulado «Prospectivas antropológicas y desarrollo rural» reúne un conjunto de diez artículos agrupados todos ellos en torno a la Cátedra, inicialmente denominada de "Turismo sostenible y Desarrollo Local», y renombrada recientemente como «Territorios sostenibles y Desarrollo Local» que tiene su sede en el Centro Asociado de la UNED en Ponferrada, León, en el noroeste de España. Por primera vez la Revista Euroamericana de Antropología (REA) se plantea abordar, desde las ciencias sociales, las prospectivas de conocimiento y de desarrollo de un territorio desde distintos enfoques temáticos. En este caso el punto de unión es el territorio, su proceso histórico, la situación crítica actual y la proyección al futuro. Todo ello desde distintos enfoques, tanto epistemológicos, como disciplinares. A pesar de las distintas procedencias, especialidades y campos de estudio, los autores de estos trabajos, de un modo u otro, se encuentran vinculados a la Cátedra y participan de su modo de hacer. A saber, generar conocimiento que pueda ser aplicado para mejorar el bienestar de una comarca azotada fuertemente por el fin de la minería y que pueda al mismo tiempo, gracias a la transferencia del mismo, mantener y potenciar la identidad cultural de la comarca. Por tal motivo los artículos presentados tienen como hilo conductor este punto de partida: el fin de la economía extractiva del carbón, y miran todos ellos hacia un futuro más prometedor. 
Esta presencia tan prolongada en el tiempo de la minería ha conformado, no solamente un paisaje característico y muy dañado, sino también un modo de pensar, de sentir, de vivir y de creer. El día 16 de noviembre de 2018 cerraba el pozo Salgueiro, en Santa Cruz de Montes, en la localidad de Torre del Bierzo. Los cinco últimos mineros que entraron en el último relevo, al día siguiente ya no tendrían trabajo, como otros muchos de los miles de trabajadores que, de un modo directo $\mathrm{o}$ indirecto, trabajaron en esta potente industria comarcal. A diferencia de otros territorios nacionales o internacionales aquejados de la misma situación, la comarca del Bierzo presenta dificultades de reconversión. Su alejamiento a grandes núcleos urbanos dificulta también la posibilidad de alternativas laborales. Por todo ello era necesario un replanteamiento del modelo productivo que tenía que tener en cuenta la recuperación de las actividades agrícolas e incluso ganaderas que se llevaron a cabo antes de la llegada de la fiebre del carbón, así como también, el desarrollo de nuevas alternativas que fomenten el turismo ambiental y sostenible, la recuperación patrimonial del pasado industrial, y el desarrollo de nuevos bienes patrimoniales que estimulen nuevas formas empresariales y productivas. El reto es enorme, pero las ciencias sociales poseen herramientas prospectivas para poder llevar a cabo tal empeño, o al menos intentarlo.

Con esa intención nace el día 1 de abril del año 2011 el Observatorio Territorial del Noroeste con apoyo de la UNED, de la Universidad de León, así como también de la CIUDEN (Fundación Ciudad de la Energía dependiente del Ministerio de Industria). Esta colaboración ha sido fundamental y es el germen de la Cátedra que da cobijo a este monográfico. Según Arsenio Terrón, director de la CIUDEN, de lo que se trata es de tomar en consideración la descarbonización como palanca verde para una nueva economía centrada en las personas, en los seres humanos que habitan territorios rurales que merecen el mejor de los bienestares posibles.

El objetivo de este observatorio fue crear un espacio abierto de trabajo, reflexión interdisciplinar y conocimiento y contribuir con ello a la toma de las mejores decisiones institucionales y al fomento de las más apropiadas políticas públicas que tendrían que lidiar con la situación descrita de pérdida del modelo productivo y de crisis laboral, económica y social. El modelo fue exitoso y, fruto de esta colaboración, el día 16 de enero de 2019, la UNED y el Consorcio firmado por la Diputación de León, el Consejo Comarcal del Bierzo y el Ayuntamiento de Ponferrada firman el Convenio de creación de la Cátedra de Turismo sostenible y Desarrollo Local. Esta Cátedra insiste en el objetivo marcado por el Observatorio, pero se muestra más ambiciosa y, si cabe más abierta a la colaboración con distintas asociaciones, grupos de investigación, empresas e instituciones que tengan interés y ambición por dinamizar el territorio de un modo respetuoso con el medio ambiente, con las tradiciones y con la cultura local. Todos los artículos que reúne este monográfico se enmarcan en este objetivo y responden a esta ambición.

El monográfico comienza con el análisis de la importancia que la Unión Europea ha concedido a la cohesión territorial entre distintos espacios, y la prioridad de luchar por mejorar en los distintos indicadores propuestos para su medida. Esto 
ocurre, sobre todo, en los territorios que, a su condición de ruralidad incluyen su localización en zonas de montaña. Estos lugares se encuentran sometidos a varios olvidos y, por lo general, invisibilizados, a lo que suman la pérdida constante de población desde hace décadas. Son estos espacios un claro ejemplo de la falta de cohesión territorial. Por tal motivo, el artículo del prof. Montes aborda la realidad de un valle en el noroeste de la comarca del Bierzo que, a pesar de su escasa población y su condición periférica recibe más de quince mil visitantes al año, según palabras de su alcalde. Se trata de la localidad de Balboa. El es caso resulta significativo, no solo por este número de visitantes, sino por haber logrado mantener estable su población en los últimos años en un modelo de resistencia rural. El artículo analiza el conjunto de distintas circunstancias que han posibilitado esta realidad. Así, de este modo, se exponen las distintas políticas públicas llevadas a cabo en torno a las infraestructuras, y a las iniciativas propuestas desde el Ayuntamiento para el desarrollo local. Además se resalta también cómo las iniciativas públicas ayudan pero deben de estar acompañadas de iniciativas emprendedoras privadas que apuesten por las empresas rurales. Es más, el caso de Balboa se propone como modelo de continuidad en las políticas públicas. A pesar del cambio de corporación municipal, el modelo propuesto de desarrollo no se ha resentido, al contrario, el nuevo regidor municipal ha tomado el testigo con fuerza y mantiene una apuesta firme por esto que hemos llamado la resistencia rural.

A continuación el profesor y co-director de la Cátedra, el profesor Calvo junto con la investigadora y experta en cooperativismo social, María Ramón esbozan las posibilidades de conformación de un nuevo modelo económico basado en el emprendimiento y la economía social. Este trabajo resulta de gran importancia, pues pone de manifiesto la necesaria conformación de grupos multidisciplinares para abordar temas complejos como son: la cohesión entre territorios y los procesos de reconversión productiva. En la primera parte del artículo, desde el punto de vista de la economía social se establecen las bases de lo que podría ser un nuevo paradigma basado no tanto en el mercado y en la producción, sino en las personas. Fruto de este paradigma se presenta el proyecto Incuba, experiencia pionera de consiste en la formación de redes de emprendedores en entornos rurales que abarca, aparte de la formación de los participantes y de los habitantes de este entorno local, la preocupación por un aumento de las competencias emprendedoras de cada uno de los pobladores del espacio rural, así como de su creatividad para el afloramiento de nuevos recursos en el territorio.

El tercer artículo del presente monográfico aborda una temática relativamente nueva, pero de un destacado interés para el desarrollo rural y la cohesión territorial, como es el caso de la tecnología y sus posibilidades de conexión entre lo local y lo global, lo que algunos antropólogos acertadamente han descrito como "glocal». El artículo que firma el profesor Vega Núñez, acompañado de varios ingenieros del Centro Tecnológico INTECCA da cuenta del nacimiento del citado centro como espacio de innovación abierta y de transferencia del conocimiento, así como de retorno de la inversión hacia los territorios rurales para que la cohesión 
pueda mejorarse gracias al uso de las nuevas tecnologías. Este texto resulta de gran importancia pues su contenido describe cómo el citado Centro ha sentado las bases para la puesta en marcha de la Cátedra. Pero, al mismo tiempo, también abre la puerta a la necesaria colaboración entre las ciencias sociales, las humanidades y la tecnología. El futuro que se propone para la comarca pretende caminar en esta dirección. Ya no es posible pensar un desarrollo para los espacios rurales sin contar con la tecnología, por tal motivo, parecen cada vez más pertinentes los trabajos colaborativos entre expertos en ciencias sociales y expertos en nuevas tecnologías y en el mundo digital, tal y como este texto pone de manifiesto.

En el artículo que sigue, el director del Consorcio Público Universitario de la UNED, el profesor Vega Nuñez y el Director de la Cátedra de Turismo sostenible y desarrollo local, el profesor Calvo González abordan la creación de primera mano del Observatorio Territorial del Noroeste, eje central de los proyectos de conocimiento aplicado al desarrollo rural y local de la comarca. Desde el año 2011 y con un enfoque "bottom up", el observatorio ha sido promotor de actividades y proyectos que, bajo la combinación de conocimiento, aplicabilidad del mismo y transferencia entre la población local a través de cursos, seminarios y talleres ha contribuido a crear valor y confianza en el territorio. En el artículo se expone el proceso de surgimiento de la idea, el desarrollo de la misma y los frutos obtenidos de participación de los distintos agentes sociales, económicos, ambientales y políticos de la comarca del Bierzo. En el fondo, el observatorio se ha planteado como un laboratorio de ideas en el noroeste para la creación de redes de emprendimiento local. El tiempo se ha de encargar de juzgar la idea y los logros de la misma. Por de pronto, según se nos propone en el artículo, la idea ha sido bien valorada y ha estimulado la generación de la Cátedra que ha dado pie al presente monográfico.

Los artículos que siguen presentan ya, de un modo decidido, algunas de las experiencias de conocimiento aplicado llevadas a cabo a lo largo de estos últimos años y en distintos procesos de su desarrollo. Algunas de ellas se encuentran en una fase preliminar, mientras que otras ya se encuentran consolidadas y en fase de expansión. Este es el caso del trabajo presentado por el profesor Balado sobre la senda minera, una propuesta turística que trata de unir la historia de la comarca con el patrimonio industrial y el fomento del desarrollo rural. El punto de partida se remonta a época prerromana cuando aparecen los primeros vestigios de actividad minera e industrial, consolidada posteriormente en época romana. Este aspecto debe ser considerado como uno de los elementos esenciales de la identidad colectiva que debe de ser preservado, conservado y, sobre todo, recuperado para poder convertirse en un atractivo turístico muy importante en la comarca. La senda minera, tal y como se expone en el texto del profesor Balado, trata de ofrecer un recurso coherente que presenta una sólida base histórica, cultural y, sobre todo, integradora de todo un espacio rural. El objetivo ha de ser, como se describe en el texto, mejorar el modo de vida de territorios especialmente desfavorecidos por la crisis energética y la despoblación. 
Dentro de este contexto de la actividad extractiva se presenta el trabajo del profesor e investigador Roberto Matías sobre los canales de la zona minera Las Médulas centrado en su estructura de canales romanos. Desde luego, si hay alguna imagen que proyecte la comarca del Bierzo hacia el exterior, esa es sin duda la imagen de los restos de la explotación aurífera romana denominada Las Médulas a unos veinte kilómetros de la capital de la comarca. En el año 1977, estos restos y el paisaje que la conforman fueron declarados Patrimonio de la Humanidad. Sin embargo, a juicio del profesor Matías, esta declaración pasó por alto el conjunto de canales de abastecimiento de agua imprescindibles para poder realizar el derrumbe de la montaña para la extracción del oro y que ha dado lugar a esos característicos pinachos de color rojizo característicos del paisaje. Estos canales, que en el momento actual alcanzan ya una longitud cercana a los 700 kilómetros se han considerado una obra menor, tesis que el autor de este trabajo discute razonadamente. La magnitud de este trabajo merece un reconocimiento cuanto menos similar que el concedido al paisaje conformado por los restos de la arrugia, según la denominación del naturalista romano Plinio.

En el siguiente texto, los profesores y economistas Hidalgo Alcázar, Lanero y Vázquez Burguete abordan la realidad cambiante del turismo en entornos distintos a los tradicionales de sol y playa. Este texto es un ejemplo de la necesidad de las ciencias sociales por abordar los problemas de forma multidisciplinar. La mirada de los economistas es importante cuando se trata de generar proyectos de desarrollo que se mantengan en el tiempo y que presenten sostenibilidad tanto social como económica. En este sentido la recuperación del patrimonio tradicional es un valor relevante, no solo como elemento identitario, sino como recurso económico. Esta es, sin duda, una línea que debe ser explorada en muchos de los entornos rurales de Castilla y León. Como caso concreto los autores abordan el modo de combatir la despoblación en Villar del Monte a través de la recuperación del patrimonio etnográfico y la cultura tradicional en la comarca de La Cabrera, la llamada Hurdes leonesa. El texto describe la transformación de la localidad en un pueblo-museo que le permite obtener recursos turísticos y conservar a su vez su peculiar etnografía.

$\mathrm{Al}$ abordar los problemas de los espacios rurales es necesario concentrarse en la situación de la mujer, su tradicional rol y las nuevas expectativas que el emprendimiento y las tecnologías actuales les ofrecen. De esto se ocupa el texto que presentan las profesoras e investigadoras Solórzano García, Rodríguez Guzmán y Real Castelao. Todo proyecto de desarrollo ha de tener en cuenta la perspectiva de género y más si cabe en unos espacios rurales con una población muy envejecida y masculinizada. De un modo concreto se analiza el proyecto "Quedaté» desarrollado por la asociación AFA Bierzo que trata de mejorar de un modo significativo la vida de las personas en entornos rurales creando al mismo tiempo puestos de trabajo relacionados con el cuidado. Las autores exponen además algunos de los logros alcanzados a través del emprendimiento femenino al contar con alianzas entre las instituciones públicas y asociaciones con un fin social. 
Otro de los aspectos destacados del desarrollo en zonas desfavorecidas pasa por la creación de museos que ofrezcan atractivos turísticos y mejoren el tiempo de estancia. Con esta intención se puso en marcha el proyecto de creación del Museo Nacional de la Energía con sede en la antigua central térmica de Compostilla en Ponferrada. Este proyecto, muy ambicioso, solamente se ha desarrollado primera directora e investigadora Esther Aparicio. En el texto se expone la idea germinal del museo como apuesta no solamente para crear un museo nacional, sino para que fuese un museo distinto, viable y que pudiese contribuir a los retos que la sociedad actual mantiene con la ciencia, la energía y el cambio climático. A pesar de la parcialidad en la ejecución y los motivos que la han motivado, el modelo de museo propuesto sigue siendo enormemente atractivo para una comarca que mantiene una deuda enorme con la energía del carbón.

En el artículo que cierra el monográfico, la investigadora y experta en patrimonio cultural Sara Álvarez presenta de forma prospectiva una idea de desarrollo para un espacio fuertemente golpeado por la crisis de la minería como es la comarca de Laciana. La localidad de Villablino, el centro comarcal y localidad más importante, ha sido uno de los ejes principales de la explotación minera del carbón, pero su pérdida de población en los últimos años ha sido alarmante. Muchos de los mineros ya jubilados y prejubilados han abandonado la localidad, y no hay futuro para la población joven, de modo que la sangría demográfica es especialmente significativa. Por eso, se presenta como una alternativa posible el proyecto Camminus como paso previo para la creación del Centro Cultural de los Castros de Laciana. Este proyecto pretende contar con la participación ciudadana y se propone además como un modelo de gestión cultural que sirva de plataforma para nuevos proyectos en una zona que se encuentra muy necesitada de ellos. Sería interesante retomar el análisis en el plazo de unos años para ver qué ha sido de esta prospectiva y de los distintos proyectos.

Para finalizar, me gustaría, como coordinador del número, agradecer a la Cátedra por la posibilidad que ha brindado de colaboración entre distintos especialistas en las ciencias sociales. El resultado ha sido producto de encuentros, cursos, conversaciones informales que han dado lugar a un diálogo fructífero y complejo entre especialistas diversos. Han de juzgar en todo caso los lectores el fruto de todo ello.

Por último me gustaría agradecer también a los autores por la excelente disposición hacia la corrección y mejora de los textos, así como a la dirección de la Revista Euroamericana de Antropología por la excelente disposición y acogida del presente número. 